\title{
Vinyl ethers and epoxides photoinduced copolymerization with perfluoropolyalkylether monomers
}

\author{
Giuseppe Trusiano $^{1}$ - Alessandra Vitale ${ }^{1} \cdot$ Céline Bonneaud $^{2} \cdot$ Diego Pugliese $^{1} \cdot$ Sara Dalle Vacche ${ }^{1}$. \\ Christine Joly-Duhamel ${ }^{2} \cdot$ Chadron M. Friesen $^{3} \cdot$ Roberta Bongiovanni $^{1}$
}

Received: 6 May 2020 / Revised: 7 August 2020 / Accepted: 10 August 2020 / Published online: 9 September 2020

(C) The Author(s) 2020

\begin{abstract}
New perfluoropolyalkylether (PFPAE) monomers, chain extended with different alkyl groups and functionalized with vinyl ether or epoxide end-groups, were employed, together with trimethylolpropane trivinyl ether or trimethylolpropane triglycidyl ether, to produce fluorinated copolymers. The photoinduced cationic polymerization was investigated, and the PFPAE-based copolymer properties were thoroughly characterized. Interesting surface properties and two different values of refractive index were observed: thus, these fluorinated copolymers can be suitable materials for the manufacture of self-cleaning coatings and optical waveguides.
\end{abstract}

Keywords Perfluoropolyalkylethers $\cdot$ Cationic polymerization $\cdot$ UV curing $\cdot$ Sliding angle $\cdot$ Refractive index

\section{Introduction}

The photoinduced cationic polymerization of vinyl ether or epoxy-based formulations is nowadays a well-established process, which owes its development and implementation in several industrial fields, such as inks, adhesives, coatings, and electronics, to its significant advantages: the photoinduced process is fast, does not require either solvent or heating, there is no inhibition by oxygen, products show low shrinkage, good mechanical and adhesion properties [1-4].

Electronic supplementary material The online version of this article (https://doi.org/10.1007/s00396-020-04723-3) contains supplementary material, which is available to authorized users.

Giuseppe Trusiano

giuseppe.trusiano@polito.it

Alessandra Vitale

alessandra.vitale@polito.it

1 Department of Applied Science and Technology, Politecnico di Torino, Corso Duca degli Abruzzi 24, 10129 Torino, Italy

2 Institut Charles Gerhardt Montpellier, University of Montpellier, CNRS, ENSCM, Cedex 5, 34296 Montpellier, France

3 Department of Chemistry, Trinity Western University, 7600 Glover Road, V2Y 1Y1 Langley, BC, Canada
The design of new monomers suitable for cationic photopolymerization processes is therefore interesting. In this context, perfluoropolyalkylethers (PFPAEs) are attractive building blocks. They are non-toxic [5-8] and show exceptional properties: high thermal, chemical, corrosion, and weather resistances, very low refractive index, surface tension, glass transition temperature, adhesion, and friction [9-12]. Therefore, they have found applications as lubricants, surfactants, and finishing agents. Several PFPAE structures exist: they are made up of one or two of the following repetitive units: $-\left(\mathrm{CF}_{2} \mathrm{O}\right)_{-},-\left(\mathrm{CF}_{2} \mathrm{CF}_{2} \mathrm{O}\right)-,-\left(\mathrm{CF}_{2} \mathrm{CF}_{2} \mathrm{CF}_{2} \mathrm{O}\right)-$, and $-\left(\mathrm{CF}\left(\mathrm{CF}_{3}\right) \mathrm{CF}_{2} \mathrm{O}\right)-. \mathrm{CF}_{3} \mathrm{O}-, \mathrm{C}_{2} \mathrm{~F}_{5} \mathrm{O}-, \mathrm{C}_{3} \mathrm{~F}_{7} \mathrm{O}-$, and $\mathrm{COFC}_{2} \mathrm{~F}_{4}$ - are the end-groups, depending on the synthesis route $[9,11]$. These end-groups can be functionalized in a large variety of ways, as described in several reviews [9]. In the past years, an increasingly growing number of attempts to functionalize PFPAEs with photoreactive terminal groups, exploitable as monomers/oligomers for preparing polymers via photopolymerization reactions have also been observed [ 9 , 13-15]. The UV-cured fluorinated copolymers obtained, mostly acrylic, have been proposed as fouling-release coatings, microfluidic devices, non-flammable polymeric electrolytes for lithium ion batteries, microlithography resins, etc. $[13,14,16,17]$. A few examples of PFPAE monomers bearing allylic and epoxy groups are also reported [18].

In our recent works, we showed that a very low amount $(<$ 5 wt $\%$ ) of monofunctional PFPAE epoxides 
photocopolymerized with common epoxides guaranteed a significant modification of the surface properties [13, 14, 19-22], even more effective than fluorinated vinyl ethers and epoxides used previously, which pose safety issues due to the long fluoroalkylic chain [20, 23].

In this work, we describe the cationic photocopolymerization of new difunctional PFPAE vinyl ethers and epoxides with traditional non-fluorinated monomers, using a relatively high PFPAE comonomer content (25 wt \%). The photopolymerization reaction of the fluorinated copolymers was studied, and their surface and bulk properties have been characterized as well.

Biphasic morphologies have been obtained resulting into a surface segregation of the PFPAE comonomers and into peculiar optical properties so that these materials can be suitable for applications as high-performance coatings and polymer optical waveguides.

\section{Materials and methods}

\section{Materials}

The difunctional fluoromonomers employed in this work are reported in Fig. 1.
They were synthesized starting from PFPAE diacyl fluoride or dicarboxylic acid. These products were chain extended with alkyl groups and functionalized with vinyl ether and epoxide end-groups: monofunctional products were also present. The average functionality, estimated by ${ }^{19} \mathrm{~F}-\mathrm{NMR}$ analyses, is reported in Table 1. Details about the synthesis, functionalization, and characterization of the functional PFPAE derivatives used in this work can be found in a forthcoming paper [24].

The hydrogenated (i.e., non-fluorinated) comonomers used are trimethylolpropane trivinyl ether (TVE, kindly provided by BASF Germany) and trimethylolpropane triglycidyl ether (TGE, purchased by Sigma-Aldrich). Triphenylsulfonium hexafluorophosphate salts, $50 \mathrm{wt} \%$ in propylene carbonate, purchased from Sigma-Aldrich (Italy), was used as the cationic photoinitiator.

\section{Photoinduced polymerization}

The UV-reactive formulations were prepared by mixing $75 \mathrm{wt} \%$ of the hydrogenated resin and $25 \mathrm{wt} \%$ of the PFPAE monomer. In each formulation, $2 \mathrm{wt} \%$ of the photoinitiator was added. The details of the formulations used in this work are collected in Table 2.

The UV-sensitive mixtures were coated onto a glass substrate, using a wire-wound applicator. The glass substrate used
Fig. 1 PFPAE comonomers used in the UV-induced copolymerization with non-fluorinated monomers. The values of the repeat units $(m)$ can be found in Table 1

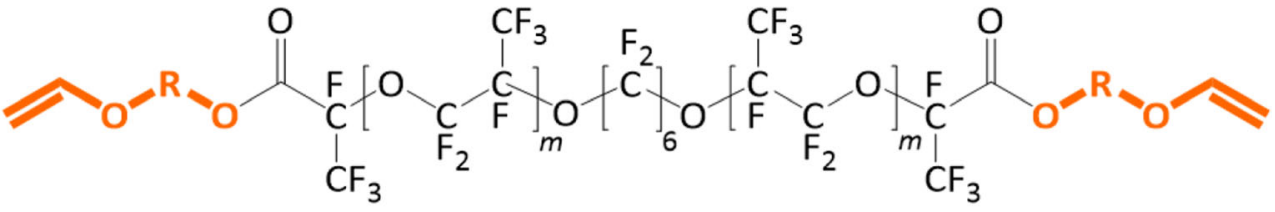

PFPAE VINYL ETHERS
EGVE (ethylene glycol vinyl ether) $\rightarrow \mathrm{R}=-\mathrm{CH}_{2}-\mathrm{CH}_{2}-$
BGVE (1,4 butylene glycol vinyl ether) $\rightarrow \mathrm{R}=-\mathrm{CH}_{2}-\mathrm{CH}_{2}-\mathrm{CH}_{2}-\mathrm{CH}_{2}-$
DEGVE (di-ethylene glycol vinyl ether) $\rightarrow \mathrm{R}=-\mathrm{CH}_{2}-\mathrm{CH}_{2}-\mathrm{O}-\mathrm{CH}_{2}-\mathrm{CH}_{2}-$

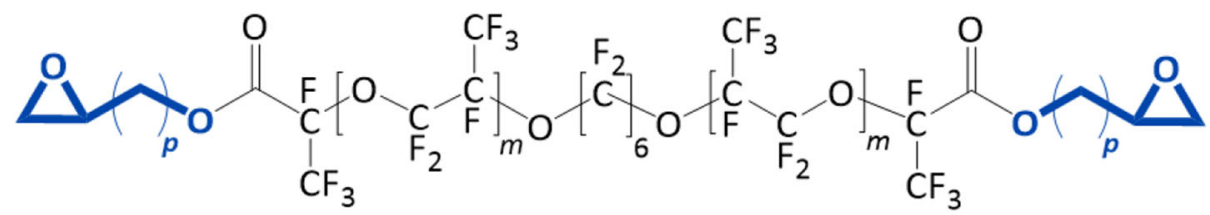

\section{PFPAE EPOXIDES}


Table 1 Number of repeat units, average molecular weight $\left(\mathrm{M}_{n}\right)$, difunctional content, and average functionality (from ${ }^{19} \mathrm{~F}-\mathrm{NMR}$ spectra) of the functionalized PFPAE monomers

\begin{tabular}{lrlll}
\hline System & $m$ & $\begin{array}{l}\text { PFPAE average } \mathrm{M}_{n} \\
(\mathrm{~g} / \mathrm{mol})\end{array}$ & $\begin{array}{l}\text { PFPAE difunctional content } \\
(\mathrm{mol} \%)\end{array}$ & $\begin{array}{l}\text { PFPAE average } \\
\text { functionality }\end{array}$ \\
\hline PFPAE-EGVE & 6 & 1740 & 56 & 1.56 \\
PFPAE-BGVE & 8 & 2130 & 88 & 1.88 \\
PFPAE-DEGVE & 7 & 2000 & 43 & 1.53 \\
PFPAE-MO & 12 & 2720 & 63 & 1.63 \\
PFPAE-EO & 8 & 2130 & 41 & 1.41 \\
PFPAE-PO & 10 & 2530 & 58 & 1.58 \\
\hline
\end{tabular}

was a microscope slide (pre-cleaned/ready-to-use) purchased from Thermo-Scientific, used as received without any surface treatment.

The samples were irradiated by means of a high-pressure mercury arc lamp Dymax ECE (predominately producing UV-A light (400-320 nm) and some amount of UV-B light (320-280 nm)) [25], using a total light intensity of $150 \mathrm{~mW} /$ $\mathrm{cm}^{2}$ for $5 \mathrm{~min}$. Samples with different thickness, ranging from 100 to $300 \mu \mathrm{m}$, were prepared. Light intensity was measured with a UV Power Puck II digital radiometer.

After irradiation, the samples had been stored for at least $24 \mathrm{~h}$ at room temperature before properties were evaluated. This wait time allowed for complete dark post-curing reactions, which are typical of a cationic process.

\section{Polymer characterization}

The conversion of the photopolymerization reaction was monitored by Fourier transform-infrared (FT-IR) spectroscopic analysis and by photodifferential scanning calorimetry (photo-DSC).

Real-time FT-IR spectroscopic analyses were performed using a Nicolet iS50 FT-IR spectrometer (Thermo Fisher Scientific). Simultaneously with the FT-IR scan acquisition in transmission mode, resin thin films (i.e., about $10 \mu \mathrm{m}$ on a $\mathrm{Si}$ wafer as substrate) of the reactive monomeric mixtures were irradiated with an UV Hamamatsu LC8 lamp, provided of an optical fiber, having an intensity equal to $100 \mathrm{~mW} / \mathrm{cm}^{2}$. Light intensity was measured with an UV Power Puck II digital radiometer.

Polymerization conversion was followed by monitoring the decrease of the absorbance of the vinyl ether groups at $1620 \mathrm{~cm}^{-1}$ or of the epoxy groups in the region 900 $920 \mathrm{~cm}^{-1}$ as a function of the irradiation time.

FT-IR spectra were also recorded in attenuated total reflectance (ATR) mode, employing a Nicolet Smart iTX accessory equipped with an ATR diamond crystal, to check the final monomer-to-polymer conversion at the polymer surface after dark-curing (i.e., $24 \mathrm{~h}$ at room temperature).

Polymerization kinetics was also studied by photo-DSC analysis, estimating the heat of the photopolymerization reactions by means of a Mettler-Toledo DSC1 STARe System, appropriately equipped with a Hamamatsu LC8 lamp with two beams, one for the sample and the other for the reference, as reported in previous works [26, 27]. To ensure equal illumination conditions throughout the sample volume, about $5 \mathrm{mg}$ of each formulation were cured in open aluminum pans. The sample was extensively flushed with nitrogen. Two scans were performed on each sample to subtract the thermal effect of UV irradiation from the photocuring experiment, each one consisting of $4 \mathrm{~min}$ of conditioning at $T=25{ }^{\circ} \mathrm{C}, 20 \mathrm{~min}$ of irradiation, and $4 \mathrm{~min}$ without UV light. The measurements were carried out with a light intensity of $25 \mathrm{~mW} / \mathrm{cm}^{2}$ and at room temperature, the increase of temperature due to the
Table 2 Composition details and functionality of the different investigated UV-reactive systems

\begin{tabular}{lllll}
\hline Sample & $\begin{array}{l}\text { PFPAE monomer } \\
(\mathrm{wt} \%)\end{array}$ & $\begin{array}{l}\text { Resin } \\
(\mathrm{wt} \%)\end{array}$ & $\begin{array}{l}\text { PFPAE/resin molar } \\
\text { ratio }\end{array}$ & $\begin{array}{l}\text { Average } \\
\text { functionality }\end{array}$ \\
\hline TVE & - & 100 & 0.00 & 3.00 \\
PFPAE-EGVE + & 25 & 75 & 0.04 & 2.94 \\
$\quad$ TVE & 25 & 75 & 0.03 & 2.96 \\
PFPAE-BGVE + & & 75 & 0.03 & 2.95 \\
$\quad$ TVE & 25 & 100 & 0.00 & 3.00 \\
PFPAE-DEGVE + & & 75 & 0.04 & 2.95 \\
TVE & - & 75 & 0.05 & 2.93 \\
TGE & 25 & 75 & 0.04 & 2.94 \\
PFPAE-MO + TGE & 25 & & \\
PFPAE-EO + TGE & 25 & & \\
PFPAE-PO + TGE & 25 & &
\end{tabular}


irradiation of the lamp being less than $1{ }^{\circ} \mathrm{C}$ at the end of the reaction. The reaction was considered completed when it was no longer possible to detect a change in heat flux. The total heat of reaction was then calculated by integrating the area under the exothermic peak [28]. The conversion $(\chi)$ over time was calculated by Eq. (1):

$\chi=\frac{\int_{0}^{t} \frac{\mathrm{d} H}{\mathrm{~d} t} \mathrm{~d} t}{\Delta H_{\text {theor }}}$

where $\mathrm{d} H / \mathrm{d} t$ is the heat flow released by the sample during the photocuring and $\Delta H_{\text {theor }}$ is estimated considering the heat of reaction of 60 and $84 \mathrm{~kJ} / \mathrm{mol}$ for the polymerization of the epoxy [29] and vinyl-ether monomers [30], respectively.

The insoluble fraction of the crosslinked samples (gel content) was evaluated using the weight loss of the network after a $24 \mathrm{~h}$ extraction by 1:1 dichloromethane:pentafluorobutane (DCM:PFB) solution (expressed in weight fraction) at room temperature (ASTM D2765-16) [31]. The crosslinked fraction was then calculated by dividing the mass of the dry sample after extraction by the mass of the original sample.

The thermal stability was determined by thermogravimetric analysis (TGA) using a Mettler Toledo TGA/SDTA-851 instrument. Approximately $10 \mathrm{mg}$ of the sample were placed in an alumina crucible and heated from room temperature to $800{ }^{\circ} \mathrm{C}$ under inert atmosphere $(60 \mathrm{~mL} / \mathrm{min})$, with a heating rate of $10^{\circ} \mathrm{C} / \mathrm{min}$.

Differential scanning calorimetry (DSC) thermograms were recorded using a Mettler-Toledo DSC1 STARe System from -100 to $50^{\circ} \mathrm{C}$ using a heat $/ \mathrm{cool} /$ heat method at a heating and cooling scanning rates of $10^{\circ} \mathrm{C} / \mathrm{min}$, under nitrogen flux. The glass transition temperature $\left(T_{\mathrm{g}}\right)$ was determined using the midpoint of the heat capacity jump on the second heating cycle thermogram.

To evaluate the copolymers wettability, static contact angle measurements were performed with a FTA $1000 \mathrm{C}$ instrument, equipped with a video camera and image analyzer, at room temperature with the sessile drop technique. At least three measurements were performed on each sample and the values averaged. The probe liquids were water and hexadecane, whose surface tensions are 72.1 and $28.1 \mathrm{mN} / \mathrm{m}$, respectively. The surface energy was calculated starting from the contact angle values by the Owens-Wendt's geometric mean method [32].

Contact angle was also estimated by dynamic measurements: they were performed by increasing the drop volume in the wetting process (advancing contact angle) and then decreasing it in the de-wetting phase (receding contact angle). The syringe needle remained in the drop during the whole process. In the first wetting phase, a $5 \mu \mathrm{L}$ drop was formed on the solid surface and then slowly increased in volume, reaching a maximum volume of $15 \mu \mathrm{L}$. In the second phase, the surface was de-wetted and the drop size reduced. The whole cycle was repeated three times at $1 \mu \mathrm{L} / \mathrm{s}$, with a delay time of $1 \mathrm{~s}$ between each cycle. The contact angle hysteresis $(\mathrm{CAH})$ was calculated as the difference between the measured advancing and receding contact angles.

Sliding angle measurements [33] were performed using the same FTA $1000 \mathrm{C}$ apparatus, equipped with a tilting stage. After placing a $20 \mu \mathrm{L}$ liquid drop on the test surface, the film was tilted at $0.5 \%$ s.

The refractive index ( $n$ ) of the polymeric films was measured at two different wavelengths (633 and $825 \mathrm{~nm}$ ) by prism-coupling technique (Metricon, model 2010) [34-36]. Ten scans were performed for each wavelength. Estimated error of the measurement was \pm 0.001 .

\section{Results and discussion}

The difunctional PFPAE monomers with vinyl ether and epoxide end-groups were copolymerized with trifunctional hydrogenated resins exploiting the UV-induced cationic polymerization.

The UV-reactive formulations were prepared by mixing $75 \mathrm{wt} \%$ of the hydrogenated resin and $25 \mathrm{wt} \%$ of the PFPAE monomer: this concentration was chosen evaluating the compatibility between the hydrogenated and the fluorinated comonomers with the varying of the PFPAE content in the photocurable mixtures. Among the many compositions investigated, amounts of fluorinated comonomers higher than the $25 \mathrm{wt} \%$ gave a macroscopic phase-separation at the liquid state as they were highly immiscible with the hydrogenated resins. Whereas, formulations containing $25 \mathrm{wt} \%$ of PFPAEs ensure the formation of an UV-cured network whose properties are the combination of those exhibited by the PFPAEbased comonomers with the ones displayed by the hydrogenated comonomers.

The PFPAE comonomers were transparent (Fig. 2a) although biphasic at molecular level since their structure containing a PFPAE chain is linked to alkyl-spacers bearing hydrogenated reactive end-groups [37]. The formulations containing $25 \%$ of PFPAEs appeared whitish (Fig. $2 \mathrm{~b}$ ): this heterogeneity is also reflected in the photocured copolymers. Indeed, a microscale phase separation occurs between the fluorinated and the hydrogenated phases, the latter formed by the non-fluorinated resins and the hydrogenated segments of the PFPAE products. Therefore, the photoinduced cationic copolymerization is expected to take place in the hydrogenated domains: it ensured the formation of a solid UV-cured network, colored at a visual inspection (Fig. 2c), as what often happens due to the high exothermicity of the cationic polymerization reaction. Morphological features of the systems will be discussed later in the paper.

It is important to notice that the use of low molecular weight trifunctional hydrogenated comonomers (i.e., TVE 
Fig. 2 Pictures of a PFPAE monomer, $\mathbf{b}$ photocurable mixture before irradiation, and $\mathbf{c}$ photocrosslinked copolymer film

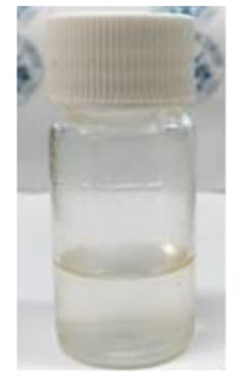

a)

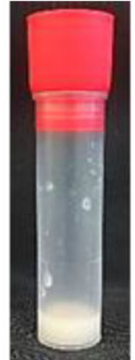

b)

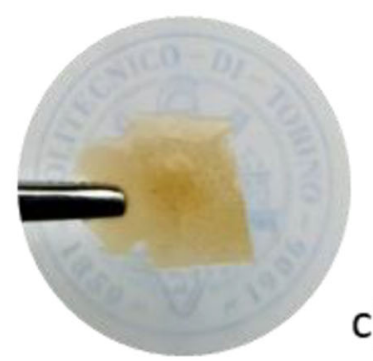

and TGE) allowed to significantly improve the mechanical properties showed by the fluorinated homopolymers [24]. In fact, after photocuring, the PFPAE homopolymers are highly viscous semi-solid materials and cannot be used as engineering materials (e.g., coatings). Whereas, the investigated copolymers appear as tight-crosslinked solid networks once UV cured (Fig. 2c).

The photopolymerization kinetics was studied through real-time FT-IR, monitoring the decrease of the intensity of the band of the double bond $\left(1620 \mathrm{~cm}^{-1}\right)$ for the vinyl ether copolymers, and of the band of the oxirane ring (900$920 \mathrm{~cm}^{-1}$ ) for the epoxide copolymers, during the UV light exposure of the sample.

The conversion curves of the PFPAE copolymers are reported in Fig. 3 and compared with the homologous homopolymers obtained from TVE and TGE. The kinetic behavior of the PFPAE-based copolymers was also studied using the photoDSC technique [16, 28]. The curves representing the first derivative of the conversion as a function of time (that is the polymerization rate) are plotted in Fig. 4 as a function of conversion for the vinyl ether (a) and the epoxy systems (b). Table 3 reports the final conversion values measured by photo-DSC analysis and estimated by real-time FT-IR spectroscopy.

As suggested by both FT-IR (Fig. 3) and photo-DSC (Fig. 4) data, the curves feature the kinetic regimes and the complex mechanisms characterizing the photopolymerization reactions of multifunctional systems, as discussed in the literature [2,38-42]. Although the

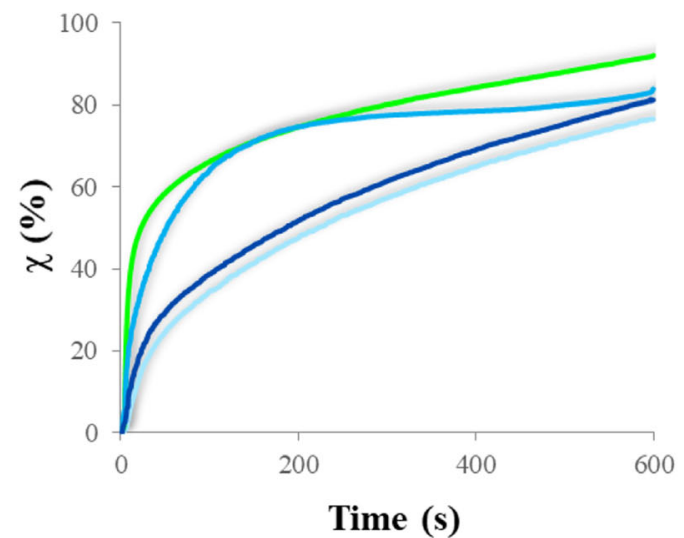

a) average functionality is not the same for all reactive systems, ranging from 2.93 to 3.00 (see Table 2), one can suggest that the presence of the PFPAE monomers reduces the reactivity; however, all systems reach more than $40 \%$ conversion in less than 3 min (Fig. 3).

Observing Fig. 4 in particular, it is clear that vinyl ethers are more reactive than epoxides; the rate until the maximum of the kinetic curves is higher for the vinyl ether systems than the epoxides. The major reactivity of the vinyl ether copolymers compared with the epoxy copolymers is also confirmed by the FT-IR data about the degree of conversion reached after 10 min of irradiation: the copolymers with vinyl ether functionalities reach conversion values of around $80 \%$ (Fig. 3a; Table 3), while those functionalized with epoxy rings reach conversion degrees of around $70 \%$ (Fig. 3b; Table 3). The higher reactivity of vinyl ether monomers can be first attributed to the presence of electron rich carbon-carbon double bonds and to the stabilization by resonance of carbocations formed during the propagation. Moreover, the lower $T_{\mathrm{g}}$ of the polymerized vinyl ether networks (data shown below) helps to reduce the retarding effects caused by the matrix vitrification that occurs when the $T_{\mathrm{g}}$ of the polymerizing network reaches the curing temperature. As the glass transition of the epoxides is about $10{ }^{\circ} \mathrm{C}$ above the one of the vinyl ether monomers, the vitrification causes an anticipated stop of the polymerization reaction in the former case: the diffusion of the unreacted epoxy chains and monomers is inhibited and they remain trapped within the glassy network [2, 43-47].

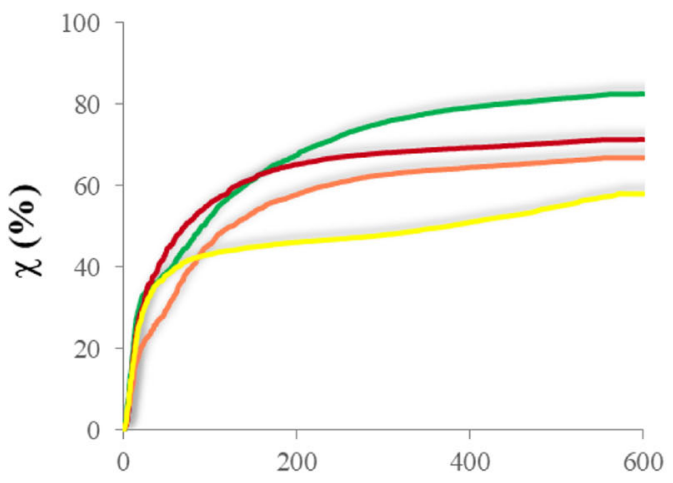

Time (s) b)

Fig. 3 Real-time FT-IR conversion curves of the different systems. a - TVE, $\lrcorner$ PFPAE-EGVE + TVE, - PFPAE-BGVE + TVE, and - PFPAE-DEGVE + TVE; $\mathbf{b}$ - TGE, $\triangle$ PFPAE-MO + TGE, - PFPAE-EO + TGE, and - PFPAE-PO + TGE 


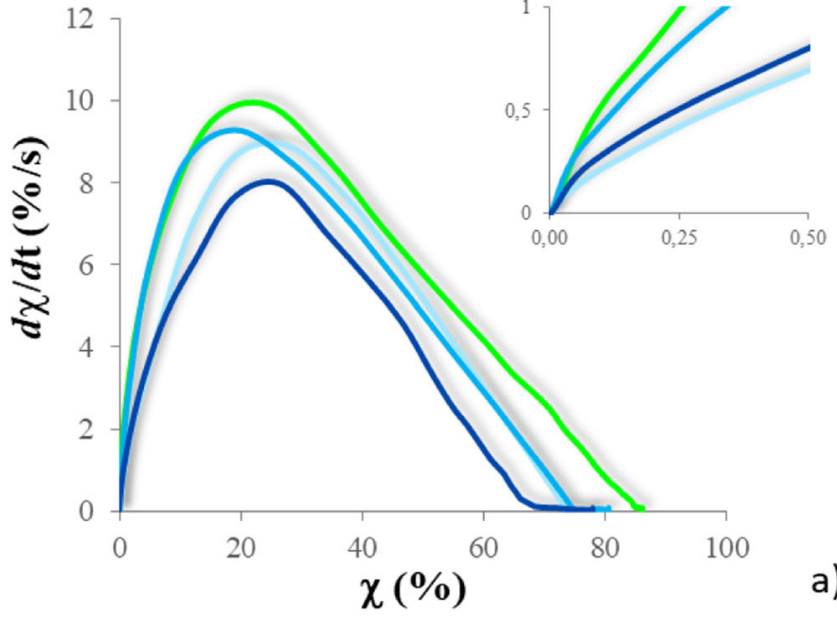

Fig. 4 First derivative of the photopolymerization conversion $(\mathrm{d} \chi / \mathrm{d} t)$ versus conversion $(\chi)$ for the different systems, by photo-DSC. a TVE, PFPAE-EGVE + TVE, - PFPAE-BGVE + TVE, and -

As mentioned above, the conversion is lower for the copolymers than for the hydrogenated homopolymers, also because there is a slight reduction of functionality. However, comparing the different copolymerization curves of Figs. 3 and 4, it seems that the length of the hydrogenated spacer between the PFPAE chains and the reactive end-groups of the fluorinated comonomers has an influence on reactivity. Similar behaviors were observed and studied for both living cationic [23, 40, 48] and radical $[49,50]$ photopolymerization. This effect was observed in the photoinduced polymerization of the macromonomers studied in [24]: the long-fluorinated chain decreased the monomer reactivity by an electron withdrawing effect, lowering the nucleophilicity of the functional group. Therefore, the rate constant of the reaction, the gel point,

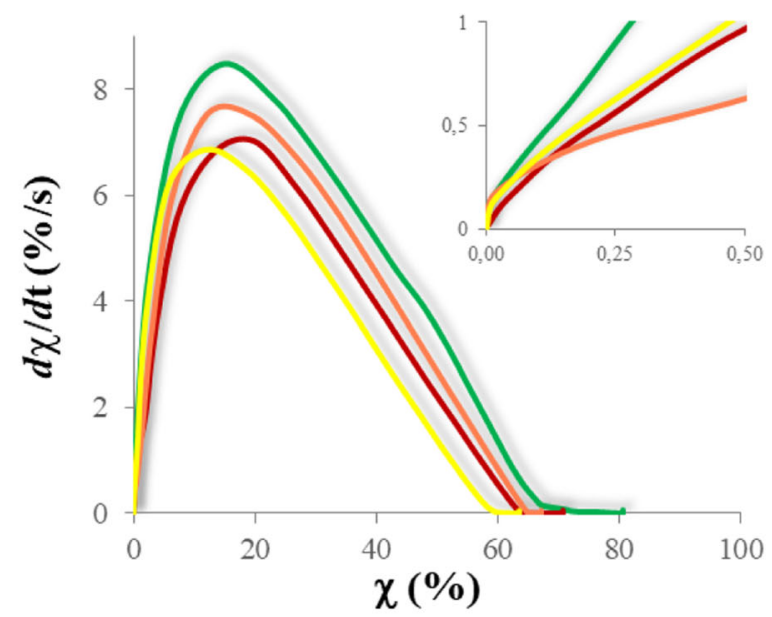

b)

PFPAE-DEGVE + TVE; $\mathbf{b}$ - TGE, PFPAE-MO + TGE, - PFPAE$\mathrm{EO}+\mathrm{TGE}$, and - PFPAE-PO + TGE

and the final conversion were found dependent on the distance between the fluorinated segment and the reactive vinyl ether/ epoxide groups. In our case, a clear correlation between reactivity and structural parameters is not present: probably, phase separation phenomena have an influence on the photopolymerization behavior of the copolymers [49, 51]. As the length of the alkyl spacing segments decreases, a greater segregation between the hydrogenated and the fluorinated monomers can occur.

The degrees of conversion of the cured products in the form of films were measured by ATR FT-IR analyses, $24 \mathrm{~h}$ after the end of the irradiation (Table 3; Figs. S1-S6 of the Supporting Information). The conversion values are quite higher than the final values estimated at the end of the irradiation both by real
Table 3 Photopolymerization study of the UV-cured copolymers: conversion $(\chi)$ values obtained by three different techniques (i.e., photo-DSC, realtime FT-IR, FT-IR ATR) and insoluble fraction values

\begin{tabular}{lllll}
\hline \multirow{2}{*}{$\begin{array}{l}l \\
\text { Sample }\end{array}$} & & & \multicolumn{2}{c}{ Insoluble fraction (\%) $^{2}$} \\
\cline { 2 - 4 } & Photo-DSC $^{\mathrm{a}}$ & FT-IR $^{\mathrm{b}}$ & FT-IR ATR $^{\mathrm{c}}$ & Gel content $^{\mathrm{d}}$ \\
\hline TVE & 86 & 92 & 97 & 92 \\
PFPAE-EGVE + TVE & 74 & 77 & 94 & 82 \\
PFPAE-BGVE + TVE & 82 & 84 & 98 & 93 \\
PFPAE-DEGVE + TVE & 78 & 81 & 96 & 90 \\
TGE & 81 & 83 & 98 & 94 \\
PFPAE-MO + TGE & 63 & 58 & 82 & 88 \\
PFPAE-EO + TGE & 67 & 67 & 85 & 86 \\
PFPAE-PO + TGE & 71 & 73 & 93 & 93 \\
\hline
\end{tabular}

${ }^{\text {a }}$ Value of the plateau in the conversion curves with an UV-light intensity of $25 \mathrm{~mW} / \mathrm{cm}^{2}$ and an irradiation time of $20 \mathrm{~min}$

${ }^{\mathrm{b}}$ Value of the plateau in the conversion curves with an UV-light intensity of $100 \mathrm{~mW} / \mathrm{cm}^{2}$ and an irradiation time of $10 \mathrm{~min}$

${ }^{\mathrm{c}}$ Value determined by single spectra taken before and after $24 \mathrm{~h}$ from the irradiation $\left(5 \mathrm{~min}\right.$ at $\left.150 \mathrm{~mW} / \mathrm{cm}^{2}\right)$

${ }^{\mathrm{d}}$ Value determined on samples after $24 \mathrm{~h}$ from the irradiation $\left(5 \mathrm{~min}\right.$ at $\left.150 \mathrm{~mW} / \mathrm{cm}^{2}\right)$, after $24 \mathrm{~h}$ of extraction by 50/50 DCM/PFB at room temperature 
time FT-IR and photo-DSC: the ATR FT-IR results confirm the presence of the spontaneous "dark curing" reaction exhibited by the cationic photopolymerization $[1,44,52]$. Interestingly, the results obtained by the ATR FT-IR measurements (Table 3 ) suggest that the longer the hydrogenated spacer between the PFPAE chain and the reactive end-groups of the fluorinated comonomers, the higher the degree of conversion.

The insoluble fraction of the photocured networks was generally good (gel content $>80 \%$, Table 3 ): these results prove that the photocured networks own good chemical stability towards halogenated solvent. However, the gel content of the copolymers was slightly lower than the one exhibited by the hydrogenated systems due to the lower conversion. Interestingly, the photocured copolymers showed a good dimensional stability: in fact, after $24 \mathrm{~h}$ of solvent extraction, a negligible swelling of the copolymers was detected (generally $<5 \%$ ).

Static contact angle measurements (Table 4) were performed on the UV-cured copolymers to evaluate their wettability with water (polar solvent) and hexadecane (non-polar solvent).

Testing the photopolymerized films made of the pure hydrogenated resins, both sides (i.e., both air and substrate sides) showed similar results: values displayed are common to polymers of medium polarity $[23,53]$. Instead, the wettability of the fluorinated copolymers was significantly different, indicating a strong increase of water and oil repellency on both the air and the glass sides of the films. In particular, the hexadecane contact angle reached ca. $70^{\circ}$ on the air side, and about $65^{\circ}$ on the substrate side (more than $50^{\circ}$ compared with the pure hydrogenated resins), as typically shown by highly fluorinated materials $[14,20]$. The copolymer wettabilities are comparable with those exhibited by homologous fluorinated homopolymers, which show water contact angles ranging from $85^{\circ}$ to $100^{\circ}$, and hexadecane contact angles in the range of $65-80^{\circ}$ [24].

These results suggest that the external surface towards air is mostly composed by the fluorinated comonomer: this is in agreement with literature data on surface migration of fluoromonomers $[14,22,54,55]$. However, with the content of fluoromonomer being quite high, there is no complete segregation of the PFPAE at the air surface; also, the surface in contact with glass is heterophasic and contains fluorine. Selective surface segregation at the air side happens when the fluoromonomer content is no more than $5 \mathrm{wt} \%$ : in these conditions the substrate side has a composition similar to the hydrogenated homopolymer [14, 22].

In agreement with the low wettabilities exhibited by these fluorinated copolymers, their surface energies (Table 4) are really low (around $20 \mathrm{mN} / \mathrm{m}$ ): in particular, the decrease of the $\gamma$ values is related to the depletion of the polar component $\left(\gamma^{\mathrm{p}}\right)$ which shows a drop of about $15 \mathrm{mN} / \mathrm{m}$ for all the copolymers with respect to the hydrogenated resins (from the overall data collected in Table 4).

Surely, the surface proprieties do not only depend on the fluorine content (Table S1 of the Supporting Information). Correlations between the contact angle and surface energy values and the fine structure of the PFPAE comonomers can be discussed in terms of the molecular weight, the presence of monofunctional monomers, and the length and mobility of the fluorinated chain [56].

Also, dynamic contact angle and contact angle hysteresis $(\mathrm{CAH})$ measurements (that is the difference between advancing and receding angles) were carried out on the resins and copolymers, on both sides of the UV-cured films (Fig. S7 of
Table 4 Static contact angle $(\theta)$, surface energy $(\gamma)$, divided in its dispersive $\left(\gamma^{\mathrm{d}}\right)$ and polar $\left(\gamma^{\mathrm{p}}\right)$ components, and contact angle hysteresis (estimated from dynamic contact angles as the difference between the advancing and the receding angles) on both air and glass sides of the UV-cured resins and copolymers

\begin{tabular}{|c|c|c|c|c|c|c|c|c|c|c|c|c|}
\hline \multirow[t]{3}{*}{ Sample } & \multicolumn{6}{|c|}{ Air side } & \multicolumn{6}{|c|}{ Glass side } \\
\hline & \multicolumn{2}{|c|}{ Static contact angle $\left(^{\circ}\right)$} & \multicolumn{3}{|c|}{$\begin{array}{l}\text { Surface energy } \\
(\mathrm{mN} / \mathrm{m})\end{array}$} & \multirow{2}{*}{$\begin{array}{l}\text { Contact angle } \\
\text { hysteresis }\left(^{\circ}\right) \\
\text { CAH }\end{array}$} & \multicolumn{2}{|c|}{ Static contact angle $\left({ }^{\circ}\right)$} & \multicolumn{3}{|c|}{$\begin{array}{l}\text { Surface energy } \\
(\mathrm{mN} / \mathrm{m})\end{array}$} & \multirow{2}{*}{$\begin{array}{l}\text { Contact angle } \\
\text { hysteresis }\left({ }^{\circ}\right) \\
\text { CAH }\end{array}$} \\
\hline & $\theta_{\mathrm{H}_{2} 0}$ & $\theta_{C_{16}} \mathrm{H}_{34}$ & $\gamma^{\mathrm{d}}$ & $\gamma^{\mathrm{p}}$ & $\gamma$ & & $\theta_{\mathrm{H}_{2} 0}$ & $\theta_{C_{16}} \mathrm{H}_{34}$ & $\gamma^{\mathrm{d}}$ & $\gamma^{\mathrm{p}}$ & $\gamma$ & \\
\hline TVE & 56 & 12 & 27 & 20 & 47 & 25 & 53 & 7 & 27 & 22 & 49 & 39 \\
\hline PFPAE-EGVE + TVE & 87 & 65 & 14 & 8 & 22 & 23 & 80 & 60 & 15 & 11 & 27 & 20 \\
\hline PFPAE-BGVE + TVE & 95 & 69 & 13 & 5 & 18 & 23 & 90 & 66 & 14 & 7 & 21 & 17 \\
\hline PFPAE-DEGVE + TVE & 83 & 63 & 14 & 10 & 24 & 20 & 73 & 62 & 15 & 16 & 31 & 21 \\
\hline TGE & 58 & 5 & 28 & 18 & 46 & 43 & 51 & 5 & 23 & 28 & 51 & 34 \\
\hline PFPAE-MO + TGE & 92 & 68 & 13 & 6 & 19 & 17 & 86 & 61 & 15 & 8 & 23 & 29 \\
\hline PFPAE-EO + TGE & 101 & 70 & 12 & 3 & 15 & 11 & 80 & 63 & 14 & 11 & 25 & 24 \\
\hline PFPAE-PO + TGE & 87 & 65 & 14 & 8 & 22 & 10 & 86 & 64 & 14 & 9 & 23 & 19 \\
\hline
\end{tabular}


the Supporting Information): the data are collected in Table 4. The CAH is mainly related to the heterogeneity and/or roughness of the outermost layers, due to the presence of both hydrophobic and hydrophilic groups at the surface [53, 57].

As reported in Table 4, the CAH values of the copolymers containing PFPAEs are generally lower than those shown by the neat hydrogenated resins, suggesting that good antistaining and self-cleaning properties can be obtained [14, 58].

As shown in Table 4, the hysteresis values of the PFPAE vinyl ether copolymers are higher than those exhibited by the PFPAE epoxide copolymers. Furthermore, a slight reduction of the hysteresis can be observed by increasing the length of the hydrogenated spacer between the fluorinated chain and the reactive end-group. However, the hysteresis behavior of the PFPAE copolymers is quite similar on both sides of the film (less than $5^{\circ}$ and $10^{\circ}$ of difference in the $\mathrm{CAH}$ values on the air and the glass sides for vinyl ethers and epoxides, respectively).

Also, sliding angle measurements were performed on the PFPAE copolymer surface. Tilting a surface on which a water drop is placed, an advancing and a receding contact angle can be measured. Increasing the tilting angle, the advancing contact angle increases, while the receding contact angle decreases. A plot of $\Delta \alpha$ (the difference between the advancing and the receding angles during tilting) versus the tilting angle can be drawn (Fig. 5) to better understand the value of the threshold sliding angle (i.e., the tilting angle at incipient droplet motion [59]).

Figure 5 shows that the threshold sliding of a $20 \mu \mathrm{L}$ deionized water drop on a UV-cured film of PFPAE-BGVE + TVE is comprised between $15^{\circ}$ and $17^{\circ}$, indicating that these copolymers are self-cleaning.
TGA experiments were also performed, in inert atmosphere $\left(\mathrm{N}_{2}\right)$, to evaluate the thermal stability of the photocured copolymers. The derivative thermogravimetric (DTG) curves are shown in Fig. 6. As it can be noticed, the thermal degradation of the PFPAE copolymers is characterized by two different main steps of weight loss, independently of the composition: these results can be attributed to a biphasic structure of the copolymers, as hypothesized above. The first degradation step begins at about $100{ }^{\circ} \mathrm{C}\left(T_{1}\right.$, Fig. 6a, b), and the maximum degradation rate is around $200{ }^{\circ} \mathrm{C}$. It was demonstrated that a facile and severe thermal degradation of PFPAE components can occur in the presence of Lewis acid (such as $\mathrm{AlF}_{3}$ ) [60] or even in presence of $\mathrm{Al}_{2} \mathrm{O}_{3}$ [61]: in these conditions, a complete degradation of fluorinated chains occurs above $180{ }^{\circ} \mathrm{C}$ $[60,61]$. In our case, as the cationic polymerization requires the formation of superacids [1] that can still be present in the photocured networks, the thermal stability of the PFPAEbased copolymers has been adversely affected. The onset temperature of the PFPAE homopolymers degradation was found to be comparable with the one exhibited by fluorinated copolymers [24]. Concerning the second weight loss at ca. $300{ }^{\circ} \mathrm{C}$ $\left(T_{2}\right.$, Fig. 6a, b), it corresponds to the degradation of the hydrogenated moieties. The temperature corresponding to the loss of the $90 \%$ of the sample $\left(T_{90 \%}\right)$ is higher than $410{ }^{\circ} \mathrm{C}$, and for temperatures higher than $600^{\circ} \mathrm{C}$, a complete degradation of the materials occurred and zero residue was detected.

However, observing both the temperature degradation data (collected in Table S2 of the Supporting Information) and the degrees of conversion of the photopolymerization reaction (Table 3), it seems that the copolymers showing a higher conversion are those more thermally resistant.
Fig. $5 \Delta \alpha$ (the difference between the advancing and the receding angles during tilting) as a function of the tilting angle, indicating the threshold sliding angle for water on the air side of a PFPAE-BGVE + TVE-cured film. The blue shadow represents the original shape of the water drop at a tilting angle of $0^{\circ}$

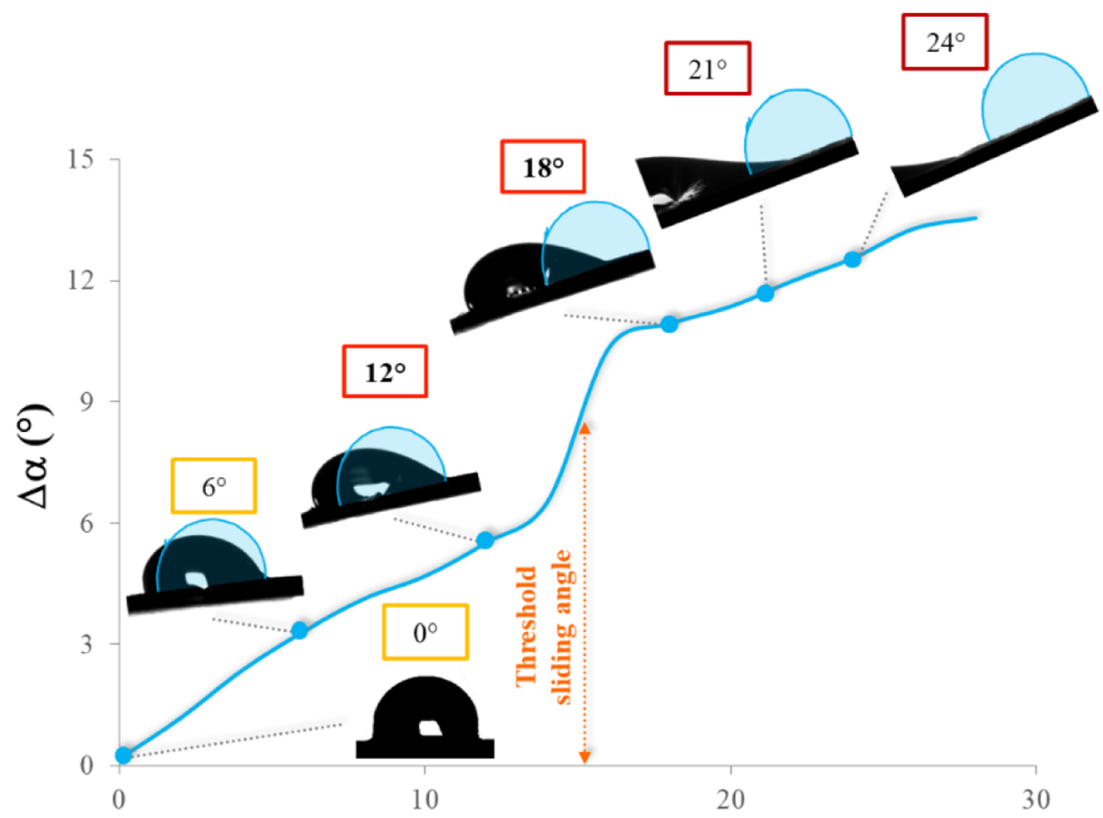

Tilting angle $\left({ }^{\circ}\right)$ 

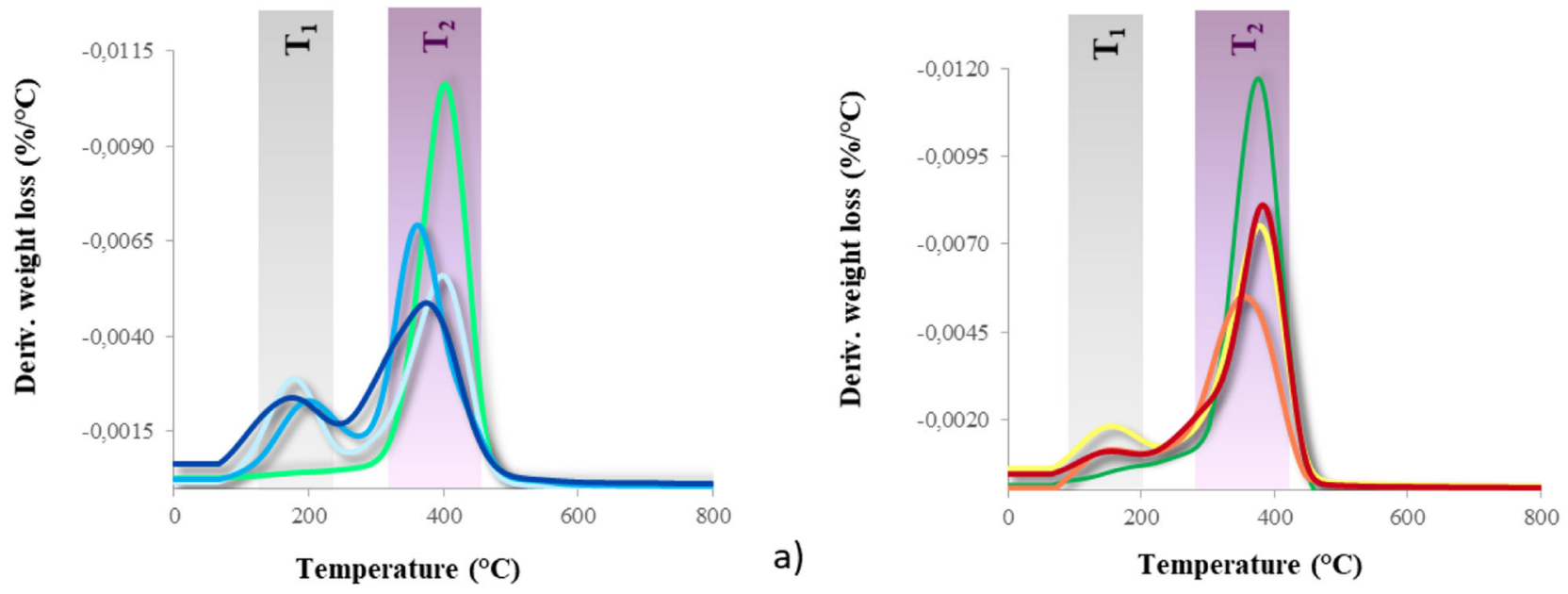

a)

Temperature $\left({ }^{\circ} \mathrm{C}\right)$

Fig. 6 Derivative thermogravimetric (DTG) curves of the UV-cured networks. a - TVE, PFPAE-EGVE + TVE, - PFPAE-BGVE + TVE, and PFPAE-DEGVE + TVE; $\mathbf{b}$ - TGE, $\neg$ PFPAE-MO + TGE, - PFPAE-EO + TGE, and - PFPAE-PO + TGE

DSC thermograms are reported in Fig. 7. All the cured copolymers are fully amorphous and clearly exhibit two different glass transitions, due to the PFPAE phase and to the non-fluorinated phase, respectively. The low-temperature phase transition of the copolymers $\left(T_{\mathrm{g} 1} \cong-65^{\circ} \mathrm{C}\right.$; Fig. 7$)$ is also present in the thermograms of the fluorinated homopolymers [24], and it is due to a fluorinated soft phase formed by the PFPAE segments. The second glass transition, which takes place at higher temperature $\left(T_{\mathrm{g} 2} \cong 20{ }^{\circ} \mathrm{C}\right.$ for the vinyl ether copolymers and $T_{\mathrm{g} 2} \cong 35{ }^{\circ} \mathrm{C}$ for the epoxide copolymers), indicates the presence of a hard hydrogenated phase, made up of the alkyl resin and the hydrogenated segments of the fluorinated monomers. $T_{\mathrm{g} 2}$ of the vinyl ether copolymers (Fig. 7a) has the same value of the glass transition of TVE ( $T_{\mathrm{g}} \cong 20^{\circ} \mathrm{C}$ ), as well as of the vinyl ether PFPAE homopolymers [24]. Whereas, $T_{\mathrm{g} 2}$ of the epoxide copolymers (Fig. 7b) occurs at the same temperature of the phase transition of TGE $\left(T_{\mathrm{g}} \cong 35^{\circ} \mathrm{C}\right)$ but is slightly higher compared with the values showed by the epoxide-fluorinated homopolymers (occurring

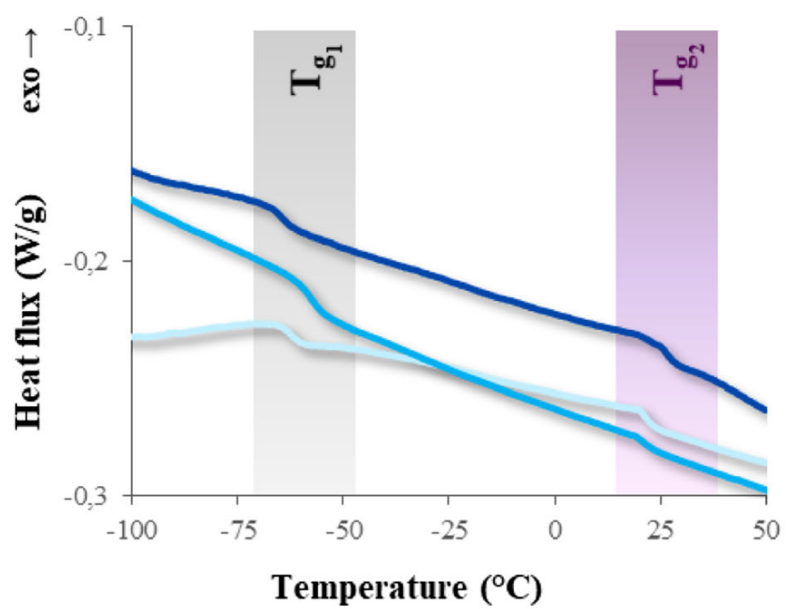

at $\cong 20^{\circ} \mathrm{C}$ ), probably due to the low conversion and the degree of phase separation [24].

The copolymers with PFPAE segments have been characterized also to evaluate their optical properties, in terms of refractive index $(n)$. Measured refractive index values are collected in Table 5. Interestingly, two different values of refractive index of the bulk of each copolymer were observed, also varying the scanning wavelength. These results are another proof of the phase-separated structure of the copolymers. As expected, the PFPAE phase shows a lower refractive index $\left(n_{1} \cong 1.31\right)[11,13]$ compared with the one exhibited by the hydrogenated moieties $\left(n_{2} \cong 1.51\right)$.

The peculiarity of these photocured copolymers, in terms of unique optical properties, is given by the combination of two factors: the presence of two different refractive indexes in the same material and their phase-separated morphology. These characteristics can make the investigated PFPAE copolymers interesting materials for optical applications, especially for the fabrication of optical waveguide devices.

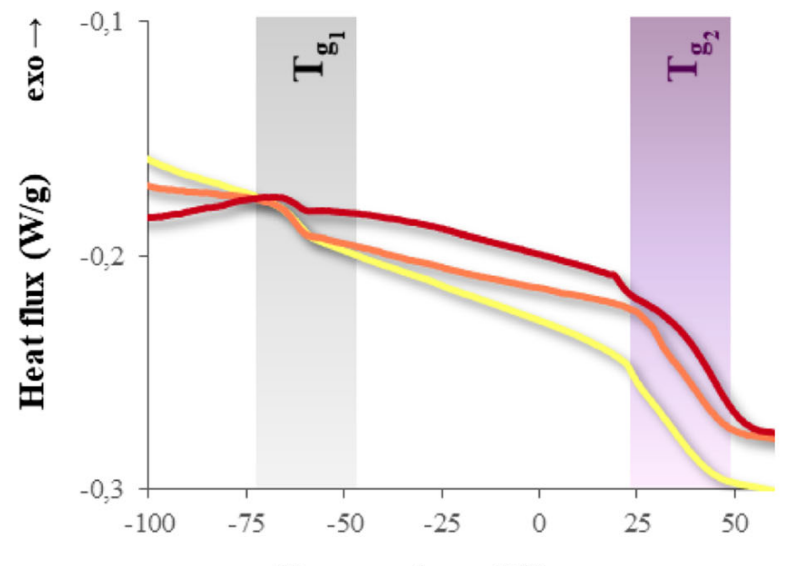

a)
Temperature $\left({ }^{\circ} \mathrm{C}\right)$

Fig. 7 DSC thermograms of the photocured copolymers. a - PFPAE-EGVE + TVE, - PFPAE-BGVE + TVE, and - PFPAE-DEGVE + TVE; $\mathbf{b}$ PFPAE-MO + TGE, - PFPAE-EO + TGE, and - PFPAE-PO + TGE 
Table 5 Refractive index of the UV-cured resins and copolymers

\begin{tabular}{|c|c|c|c|c|}
\hline \multirow[t]{3}{*}{ Sample } & \multicolumn{4}{|c|}{ Refractive index } \\
\hline & \multicolumn{2}{|c|}{$\lambda=633 \mathrm{~nm}$} & \multicolumn{2}{|c|}{$\lambda=825 \mathrm{~nm}$} \\
\hline & $n_{1}$ & $n_{2}$ & $n_{1}$ & $n_{2}$ \\
\hline TVE & - & 1.508 & - & 1.504 \\
\hline PFPAE-EGVE + TVE & 1.318 & 1.513 & 1.309 & 1.507 \\
\hline PFPAE-BGVE + TVE & 1.323 & 1.516 & 1.301 & 1.510 \\
\hline PFPAE-DEGVE + TVE & 1.324 & 1.515 & 1.322 & 1.508 \\
\hline TGE & - & 1.508 & - & 1.503 \\
\hline PFPAE-MO + TGE & 1.313 & 1.521 & 1.310 & 1.512 \\
\hline 7PFPAE-EO + TGE & 1.317 & 1.516 & 1.313 & 1.507 \\
\hline PFPAE-PO + TGE & 1.312 & 1.515 & 1.313 & 1.508 \\
\hline
\end{tabular}

In conclusion, the results collected through the characterization of the films by multiple analyses (i.e., TGA, DSC, surface analysis, and optical measurements) suggest that the morphological structure of the UV-cured copolymers, as reported in [37], is quite complex. The external surface (towards air) is mostly composed of the lower refractive index component, the fluorinated comonomer (which is heterogeneous itself, as it contains PFPAE chains and alkyl spacers ended by oxirane or vinyl ether groups). The bulk is made of both fluorodomains and hydrogenated domains; however, it is richer in hydrogenated monomer (characterized by a higher refractive index), which constitutes the $75 \mathrm{wt} \%$ of the material. We expected a hard phase formed by the non-fluorinated resins and containing the hydrogenated spacers and the reactive end-groups of the PFPAE products. This hydrogenated hard phase of PFPAE copolymers can also contain fluorochains, in an amount depending on their molecular weight and distribution [37]. The opposite face of the film, built against glass, contains both hydrogenated and PFPAE units, with the latter of lower amount than in the bulk.

\section{Conclusions}

New PFPAE derivatives, chain extended with different alkyl groups and functionalized with vinyl ether or epoxide endgroups, were employed as reactive comonomers to produce fluorinated copolymers exploiting the cationic photoinduced polymerization. The presence of fluorinated comonomers reduced the overall reactivity; however, the final conversions of the copolymeric systems were high (> $80 \%)$, as well as the gel content $(>80 \%)$.

The photocrosslinked copolymers showed marked hydrophobic and oleophobic surfaces, characterized by low hysteresis and low sliding angles. They were biphasic, as suggested by the presence of two different $T_{\mathrm{g}} \mathrm{s}$ observed in the DSC thermograms: one, at lower temperature, assigned to the softer fluorinated phase, while the other attributed to the hydrogenated domains. Two different values of refractive index were also observed, confirming a phase separated structure, in which, probably, the outermost layers are mostly made of the fluorinated comonomer (with lower refractive index), while the bulk is mainly composed of a hydrogenated network.

Thanks to these properties, the PFPAE copolymers can find applications as high-performance coatings, with antistaining and self-cleaning properties, and eventually as polymer-based waveguides for optical applications.

Funding Open access funding provided by Politecnico di Torino within the CRUI-CARE Agreement. This research project has received funding from the European Union's Horizon 2020 research and innovation program under grant agreement No. 690917-PhotoFluo and from the Natural Sciences and Engineering Research Council of Canada (NSERC), Discovery Grants Program RGPIN-2015-05513.

\section{Compliance with ethical standards}

Conflict of interest The authors declare that they have no conflict of interest.

Open Access This article is licensed under a Creative Commons Attribution 4.0 International License, which permits use, sharing, adaptation, distribution and reproduction in any medium or format, as long as you give appropriate credit to the original author(s) and the source, provide a link to the Creative Commons licence, and indicate if changes were made. The images or other third party material in this article are included in the article's Creative Commons licence, unless indicated otherwise in a credit line to the material. If material is not included in the article's Creative Commons licence and your intended use is not permitted by statutory regulation or exceeds the permitted use, you will need to obtain permission directly from the copyright holder. To view a copy of this licence, visit http://creativecommons.org/licenses/by/4.0/.

\section{References}

1. Sangermano M, Razza N, Crivello JV (2014) Cationic UV-curing: technology and applications. Macromol Mater Eng 299:775-793. https://doi.org/10.1002/mame.201300349

2. Yagci Y, Schnabel W (1988) Light-induced cationic polymerization. Macromol Symp 13-14:161-174. https://doi.org/10.1002/ masy. 19880130113

3. Chatani S, Kloxin CJ, Bowman CN (2014) The power of light in polymer science: photochemical processes to manipulate polymer formation, structure, and properties. Polym Chem 5:2187-2201. https://doi.org/10.1039/c3py01334k

4. Pappas SP (1992) Radiation curing science and technology. Springer US

5. Malinverno G, Pantini G, Bootman J (1996) Safety evaluation of perfluoropolyethers, liquid polymers used in barrier creams and 
other skin-care products. Food Chem Toxicol 34:693-650. https:// doi.org/10.1016/0278-6915(96)00023-3

6. Young CJ, Hurley MD, Wallington TJ, Mabury SA (2006) Atmospheric lifetime and global warming potential of a perfluoropolyether. Environ Sci Technol 40:2242-2246. https:// doi.org/10.1021/es052077z

7. Mountain GA, Jelier BJ, Bagia C, Friesen CM, Janjic JM (2014) Design and formulation of nanoemulsions using 2(poly(hexafluoropropylene oxide)) perfluoropropyl benzene in combination with linear perfluoro(polyethylene glycol dimethyl ether). J Fluor Chem 162:38-44. https://doi.org/10.3174/ajnr. A1256.Functional

8. Wang Z, Dewitt JC, Higgins CP, Cousins IT (2017) A never-ending story of per- and polyfluoroalkyl substances (PFASs)? Environ Sci Technol 51:2508-2518. https://doi.org/10.1021/acs.est.6b04806

9. Friesen CM, Améduri B (2018) Outstanding telechelic perfluoropolyalkylethers and applications therefrom. Prog Polym Sci 81:238-280. https://doi.org/10.1016/j.progpolymsci.2018.01.005

10. Marchionni G, Ajroldi G, Cinquina P, Tampellini E, Pezzin G (1990) Physical properties of perfluoropolyethers: dependence on composition and molecular weight. Polym Eng Sci 30:829-834. https://doi.org/10.1002/pen.760301405

11. Bongiovanni R, Medici A, Zompatori A, Garavaglia S, Tonelli C (2012) Perfluoropolyether polymers by UV curing: design, synthesis and characterization. Polym Int 61:65-73. https://doi.org/10. 1002/pi.3149

12. Ameduri B (2018) Fluoropolymers: the right material for the right applications. Chem - A Eur J 24:18830-18841. https://doi.org/10. 1002/chem.201802708

13. Vitale A, Bongiovanni R, Ameduri B (2015) Fluorinated oligomers and polymers in photopolymerization. Chem Rev 115:8836-8866. https://doi.org/10.1021/acs.chemrev.5b00120

14. Trusiano G, Rizzello M, Vitale A, Burgess J, Friesen CM, JolyDuhamel C, Bongiovanni R (2019) Modification of photocurable epoxides by new perfluoropolyalkylether alcohols for obtaining self-cleaning coatings. Prog Org Coat 132:257-263. https://doi. org/10.1016/j.porgcoat.2019.02.043

15. Bonneaud C, Decostanzi M, Burgess J, Trusiano G, Burgess T, Bongiovanni R, Joly-Duhamel C, Friesen CM (2018) Synthesis of $\alpha, \beta$-unsaturated esters of perfluoropolyalkylethers (PFPAEs) based on hexafluoropropylene oxide units for photopolymerization. RSC Adv 8:32664-32671. https://doi.org/10.1039/c8ra06354k

16. Vitale A, Quaglio M, Cocuzza M, Pirri CF, Bongiovanni R (2012) Photopolymerization of a perfluoropolyether oligomer and photolithographic processes for the fabrication of microfluidic devices. Eur Polym J 48:1118-1126. https://doi.org/10.1016/j.eurpolymj. 2012.03.016

17. Wong DHC, Vitale A, Devaux D, Taylor A, Pandya AA, Hallinan DT, Thelen JL, Mecham SJ, Lux SF, Lapides AM, Resnick PR, Meyer TJ, Kostecki RM, Balsara NP, DeSimone JM (2015) Phase behavior and electrochemical characterization of blends of perfluoropolyether, poly(ethylene glycol), and a lithium salt. Chem Mater 27:597-603. https://doi.org/10.1021/cm504228a

18. Turri S, Scicchitano M, Tonelli C (1996) End group chemistry of fluoro-oligomers: highly selective syntheses of diepoxy, diallyl, and tetraol derivatives. J Polym Sci Part A Polym Chem 34:32633275. https://doi.org/10.1002/(sici)1099-0518(19961130)34: 16<3263::aid-pola2>3.0.CO;2-v

19. Toselli M, Messori M, Bongiovanni R, Malucelli G, Priola A, Pilati F, Tonelli C (2001) Poly( $\epsilon$-caprolactone)-poly(fluoroalkylene oxide)-poly( $\epsilon$-caprolactone) block copolymers. 2. Thermal and surface properties. Polymer (Guildf) 42:1771-1779. https://doi.org/ 10.1016/S0032-3861(00)00568-1

20. Sangermano M, Bongiovanni R, Priola A, Pospiech D (2005) Fluorinated alcohols as surface-active agents in cationic photopolymerization of epoxy monomers. J Polym Sci Part A Polym Chem 43:4144-4150. https://doi.org/10.1002/pola.20865

21. Ameduri B, Bongiovanni R, Malucelli G, Pollicino A, Priola A (1999) New fluorinated acrylic monomers for the surface modification of UV-curable systems. J Polym Sci A Polym Chem 37:7787. https://doi.org/10.1002/(sici)1099-0518(19990101)37:1<77:: aid-pola9 $>3.0$. co; $2-0$

22. Trusiano G, Vitale A, Rizzello M, Bonneaud C, Joly-Duhamel C, Friesen CM, Bongiovanni R (2019) Controlling perfluoropolyalkylether rearrangements at the surface of photocured networks. Eur Polym J 121:109285. https://doi.org/10. 1016/j.eurpolymj.2019.109285

23. Vitale A, Cominotti M, Ameduri B, Bongiovanni R (2016) Semiinterpenetrating polymer networks by cationic photopolymerization: fluorinated vinyl ether chains in a hydrogenated vinyl ether network. Eur Polym J 82:122-131. https://doi.org/ 10.1016/j.eurpolymj.2016.07.009

24. Trusiano G, Pulfer J, Newton J et al (2020) Manuscript in preparation

25. Dymax ECE Series: UV light-curing flood lamp systems user guide

26. Fernández-Francos X, Salla JM, Cadenato A, Morancho JM, Mantecón A, Serra A, Ramis X (2007) Novel thermosets obtained by UV-induced cationic copolymerization of DGEBA with an spirobislactone. J Polym Sci Part A Polym Chem 45:5446-5458. https://doi.org/10.1002/pola.22289

27. Morancho JM, Cadenato A, Ramis X, Fernández-Francos X, Salla JM (2010) Thermal curing and photocuring of an epoxy resin modified with a hyperbranched polymer. Thermochim Acta 510:1-8. https://doi.org/10.1016/j.tca.2010.05.008

28. Dalle Vacche S, Geiser V, Leterrier Y, Månson JAE (2010) Timeintensity superposition for photoinitiated polymerization of fluorinated and hyperbranched acrylate nanocomposites. Polymer 51: 334-341. https://doi.org/10.1016/j.polymer.2009.11.071

29. Lohse F, Zweifel H (1986) Photocrosslinking of epoxy resins. In: Dušek K (ed) Epoxy resins and composites III. Springer, Berlin, pp 61-81

30. Sawada H (1969) Chapter 2. Heat of polymerization. J Macromol Sci C Polym Rev J 3:339-356. https://doi.org/10.1080/ 15583726908545927

31. International A (2016) ASTM D2765-16, Standard test methods for determination of gel content and swell ratio of crosslinked ethylene plastics

32. Wu S (1982) Polymer interface and adhesion. M Dekker. https:// doi.org/10.1201/9780203742860

33. Pierce E, Carmona FJ, Amirfazli A (2008) Understanding of sliding and contact angle results in tilted plate experiments. Colloids Surf A Physicochem Eng Asp 323:73-82. https://doi.org/10.1016/j. colsurfa.2007.09.032

34. Ulrich R, Torge R (1973) Measurement of thin film parameters with a prism coupler. Appl Opt 12:2901. https://doi.org/10.1364/AO.12. 002901

35. Adams AC (1979) An evaluation of the prism coupler for measuring the thickness and refractive index of dielectric films on silicon substrates. J Electrochem Soc 126:1539. https://doi.org/10.1149/1. 2129324

36. Metricon The 2010/M offers unique advantages over conventional refractometers and instruments based on ellipsometry or spectrophotometry

37. Tonelli C, Ajroldi G, Marigo A, Marega C, Turturro A (2001) Synthesis methods of fluorinated polyurethanes. 2. Effects on morphology and microstructure. Polymer (Guildf) 42:9705-9711. https://doi.org/10.1016/S0032-3861(01)00517-1

38. Bowman CN, Kloxin CJ (2008) Toward an enhanced understanding and implementation of photopolymerization reactions. AICHE J 54:2775-2795. https://doi.org/10.1002/aic.11678 
39. Goodner MD, Bowman CN (1999) Modeling primary radical termination and its effects on autoacceleration in photopolymerization kinetics. Macromolecules 32:6552-6559. https://doi.org/10.1021/ ma9901947

40. Choi W, Sawamoto M, Higashimura T (1988) Living cationic homo- and copolymerizations of vinyl ethers bearing a perfluoroalkyl pendant. Polym J 20:201-206. https://doi.org/10. 1295/polymj.20.201

41. Bulut U, Crivello JV (2005) Investigation of the reactivity of epoxide monomers in photoinitiated cationic polymerization. Macromolecules 38:3584-3595. https://doi.org/10.1021/ma050106k

42. Decker C (2002) Kinetic study and new applications of UV radiation curing. Macromol Rapid Commun 23:1067-1093. https://doi. org/10.1002/marc.200290014

43. Decker C (1998) The use of UV irradiation in polymerization. Polym Int 45:133-141. https://doi.org/10.1002/(SICI)10970126(199802)45:2<133::AID-PI969>3.0.CO;2-F

44. Decker C (1996) Photoinitiated crosslinking polymerisation. Prog Polym Sci 21:593-650. https://doi.org/10.1016/0079-6700(95) 00027-5

45. Fouassier JP, Lalevée J (2012) Cationic photoinitiating systems. Photoinitiators for polymer synthesis: scope, reactivity and efficiency. Wiley-VCH, Weinheim

46. Crivello JV, Lam JHW (1979) Photoinitiated cationic polymerization with triarylsulfonium salts. J Polym Sci A Polym Chem 17: 977-999. https://doi.org/10.1002/pol.1979.170170405

47. Decker C (2002) Light-induced crosslinking polymerization. Polym Int 51:1141-1150. https://doi.org/10.1002/pi.821

48. Shimomoto H, Fukami D, Kanaoka S, Aoshima S (2011) Fluorinated vinyl ether homopolymers and copolymers: living cationic polymerization and temperature-induced solubility transitions in various organic solvents including perfluoro solvents. J Polym Sci Part A Polym Chem 49:2051-2058. https://doi.org/10.1002/ pola. 24634

49. Bonneaud C, Burgess JM, Bongiovanni R, Joly-Duhamel C, Friesen CM (2019) Photopolymerization of maleimide perfluoropolyalkylethers without a photoinitiator. J Polym Sci Part A Polym Chem 57:699-707. https://doi.org/10.1002/pola.29311

50. Guyot B, Améduri B, Boutevin B (1999) Cinétique de polymérisation radicalaire de (méth)acrylates à chaîne latérale fluorée. Macromol Chem Phys 200:2111-2121. https://doi.org/ 10.1002/(sici)1521-3935(19990901)200:9<2111::aidmacp2111>3.3.co;2-r

51. Nelson EW, Jacobs JL, Scranton AB, Anseth KS, Bowman CN (1995) Photo-differential scanning calorimetry studies of cationic polymerizations of divinyl ethers. Polymer (Guildf) 36:4651-4656. https://doi.org/10.1016/0032-3861(95)96832-S

52. Crivello JV (1999) The discovery and development of onium salt. J Polym Sci Part A: Polym Chem 37:4241-4254. https://doi.org/10. 1002/(sici)1099-0518(19991201)37:23<4241::aid-pola1>3.0.co;2-r

53. Bongiovanni R, Malucelli G, Pollicino A, Tonelli C, Simeone G, Priola A (1998) Perfluoropolyether structures as surface modifying agents of UV-curable systems. Macromol Chem Phys 199:1099-1105. https://doi.org/10.1002/(SICI)15213935(19980601)199:6<1099::AID-MACP1099>3.0.CO;2-Q

54. Bongiovanni R, Beamson G, Mamo A, Priola A, Recca A, Tonelli C (2000) High resolution XPS investigation of photocured films containing perfluoropolyether acrylates. Polymer (Guildf) 41: 409-414. https://doi.org/10.1016/S0032-3861(99)00203-7

55. Bongiovanni R, Malucelli G, Lombardi V, Priola A, Siracusa V, Tonelli C, di Meo A (2001) Surface properties of methacrylic copolymers containing a perfluoropolyether structure. Polymer (Guildf) 42:2299-2305. https://doi.org/10.1016/S0032-3861(00)00557-7

56. Bongiovanni R, Di Meo A, Pollicino A et al (2008) New perfluoropolyether urethane methacrylates as surface modifiers: effect of molecular weight and end group structure. React Funct
Polym 68:189-200. https://doi.org/10.1016/j.reactfunctpolym. 2007.09.009

57. Bongiovanni R, Medici A, Zompatori A, Garavaglia S, Tonelli C (2012) New fluorinated acrylic monomers for the surface modification of UV-curable systems. Macromol Chem Phys 5:65-73. https://doi.org/10.1002/pi.3149

58. Zhang L, Zhou Z, Cheng B, DeSimone JM, Samulski ET (2006) Superhydrophobic behavior of a perfluoropolyether lotus-leaf-like topography. Langmuir 22:8576-8580. https://doi.org/10.1021/ la061400o

59. Samaha MA, Tafreshi HV, Gad-El-Hak M (2012) Influence of flow on longevity of superhydrophobic coatings. Langmuir 28:97599766. https://doi.org/10.1021/la301299e

60. Howell JL, Friesen CM, Shtarov AB, Thrasher JS, Waterfeld A, Pérez EW, Sullivan JF (2007) Improved thermal stability of perfluoropolyalkylethers (PFPAEs). J Synth Lubr 24:227-234. https://doi.org/10.1002/jsl.42

61. Kasai PH, Wheeler P (1991) Degradation of perfluoropolyethers catalyzed by aluminum chloride. Appl Surf Sci 52:91-106. https://doi.org/10.1016/0169-4332(91)90119-5

Publisher's note Springer Nature remains neutral with regard to jurisdictional claims in published maps and institutional affiliations.

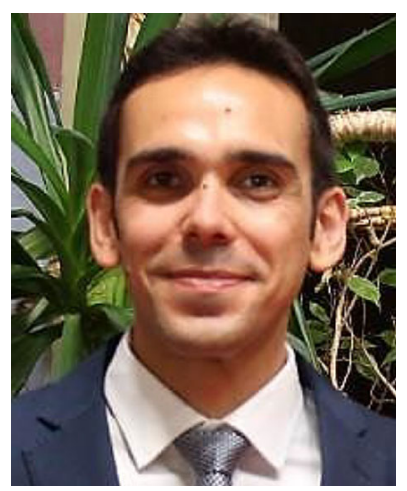

Dr. Giuseppe Trusiano received a M.Sc. in Materials Engineering at the Politecnico di Torino, where later he joined the group of Prof. Roberta Bongiovanni as $\mathrm{PhD}$ student. He participated to the European Union's Horizon 2020 program "PhotoFluo" as early bird researcher, during which he collaborated with the group of Professor Chadron M. Friesen at the Trinity Western University. His research interests mainly include the synthesis of fluoropolymers, their photopolymerization, and their use as engineering materials.

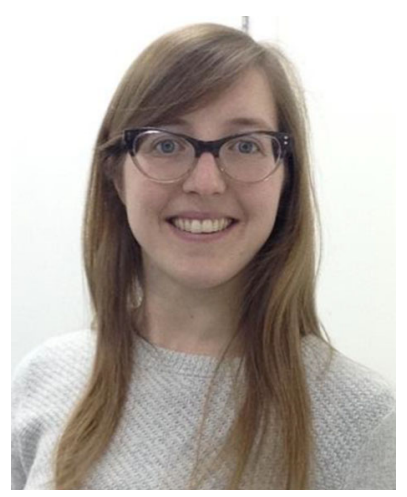

Dr. Alessandra Vitale received her $\mathrm{PhD}$ degree in Materials Science and Technology from Politecnico di Torino, in 2014. She was then engaged as research associate at the Imperial College London, and in 2016 joined Politecnico di Torino, where she currently works as Assistant Professor with time contract. She has authored more than 45 research publications in peerreviewed journals and several international conference proceedings. Her research interests include photoinduced processes, polymers surface science, and polymer nanofibrous membranes by electrospinning. 


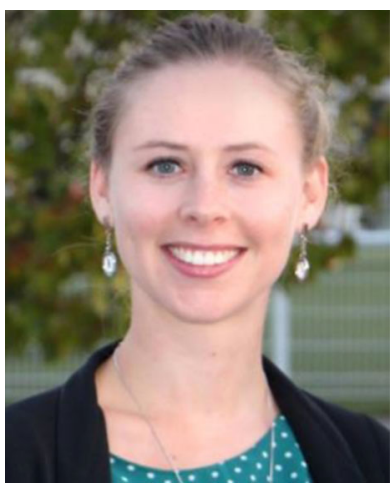

Dr. Céline Bonneaud received her M.Sc. in Chemistry from the National Polytechnique Institute of Chemical and Industrial Engineering and Technology of Toulouse in 2016. Then, she obtained her PhD working on the synthesis and photopolymerization of novel perfluoropolyalkylethers in the laboratory of Macromolecular Engineering and Architecture, in the Institute Charles Gerhardt of Montpellier, in 2019. Her Ph.D. was in the framework of PhotoFluo project (H2020) under the collaboration of Professors C. Joly-Duhamel, C. M. Friesen, and R. Bongiovanni. Now she is working in $3 \mathrm{D}$ printing silicones in Elkem.

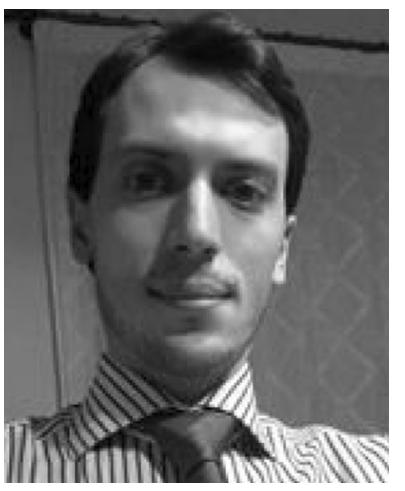

Dr. Diego Pugliese is an Assistant Professor at the Institute of Materials, Physics and Engineering of the Applied Science and Technology Department of Politecnico di Torino and RU INSTM (Consorzio INSTM, Via G. Giusti 9, 50121 Firenze, Italy) since November 2018 . In February 2014, he received his $\mathrm{PhD}$ in Physics at Politecnico di Torino. From March 2014 to October 2018, he was a postdoctoral research fellow at the Applied Science and Technology Department of Politecnico di Torino. He authored 45 peer-reviewed papers in International Journals and 2 book chapters.

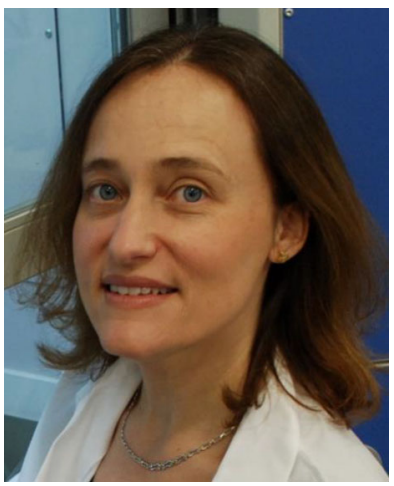

Dr. Sara Dalle Vacche holds a $\mathrm{PhD}$ in Industrial Chemical Processes from the University of Rome La Sapienza. After working for Procter \& Gamble and General Electrics, she joined the Ecole Polytechnique Fédérale de Lausanne and then Politecnico di Torino, as research fellow. She was the recipient of a Marie Heim-Vögtlin grant from the Swiss National Science Foundation and a Marie Curie Individual Fellowship from the European Commission. Her research focuses on the process-structure-property relationships in polymerbased composites and on the development of biobased composites.

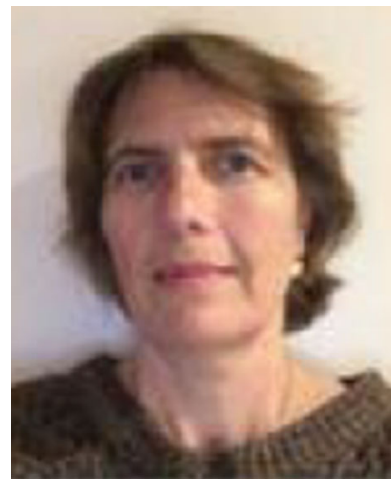

Dr. Christine Joly-Duhamel (Associate Professor at National Graduate School of Chemistry of Montpellier since 2002) is member of the team Macromolecular Engineering and Architecture of the Charles Gerhardt Institute of Material in Montpellier, where she is in charge of a major in Materials Chemistry, and is teaching rheology and mechanical properties of polymers. Her work mainly concerns the synthesis of new photopolymerizable monomers able to photopolymerize without photoinitiator. Moreover, she is expert in the physico-chemistry characterization of polymers.

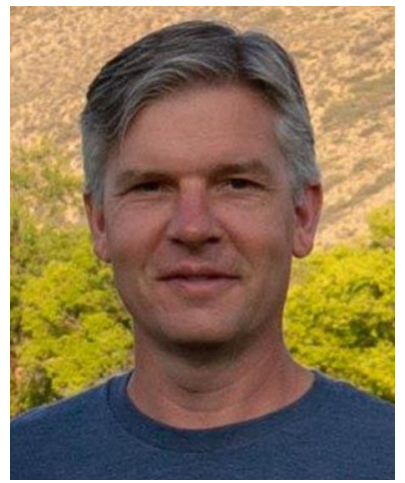

Dr. Chadron M. Friesen (Professor of Chemistry at Trinity Western University) has current interests ranging from exploring new synthetic designs and methodologies to create novel fluorinated polymers for relevant industrial applications of today or to add specified and localized amounts of fluorine to pharmaceuticals. Critical to all of these pursuits is the isolation and structural determination of these new materials and products. $\mathrm{He}$ is a member of the Division of Fluorine Chemistry of the American Chemical Society. Outside of research, Chad volunteers for Scouts Canada.

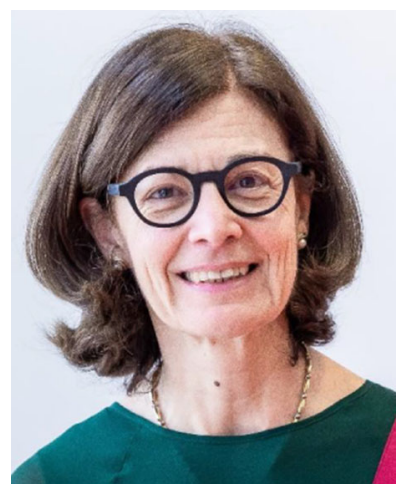

Dr. Roberta Bongiovanni, after a degree in Chemistry at the University of Turin, received a M.Sc. in Colloid and Interface Science at the University of Bristol where later she obtained her $\mathrm{PhD}$ in Physical Chemistry. She received a Doctorate Honoris Causa in Engineering by the Institut National Polytechnique Grenoble. After working at ENI for many years, she joined the Politecnico di Torino where she is now full professor of Chemistry. She has co-authored 207 publications $(h$-index $=40$ ) mostly about photoinduced polymerization of fluoropolymers and photoinduced modification of polymers. 